\title{
Causes and Health-Related Outcomes of Road Traffic Crashes in the United Arab Emirates: Panel Data Analysis of Traffic Fines
}

\author{
Ahmed Ankit $^{1}$, Samer Hamidi ${ }^{2} \&$ Mathilde Sengoelge ${ }^{3}$ \\ ${ }^{1}$ Deanship of Research and Doctoral Studies, Hamdan Bin Mohamed Smart University, UAE \\ ${ }^{2}$ School of Health and Environmental Studies, Hamdan Bin Mohamed Smart University, UAE \\ ${ }^{3}$ Department of Public Health Sciences, Karolinska Institute, Sweden \\ Correspondence: Samer Hamidi, School of Health and Environmental Studies, Hamdan Bin Mohamed Smart \\ University, UAE. Tel: 971-(4)-424-1089. E-mail: s.hamidi@hbmsu.ac.ae
}

Received: May 16, 2018 Accepted: November 15, 2018 Online Published: November 28, 2018

doi:10.5539/gjhs.v10n12p165 URL: https://doi.org/10.5539/gjhs.v10n12p165

\begin{abstract}
Aims: To investigate the main causes and consequences of road traffic injuries (RTIs) in the United Arab Emirates (UAE) and the effect of traffic fines on these injuries.

Methods: This cross-sectional study analysed road traffic deaths and injuries and panel data of monthly traffic accident fines from 2012 to 2016 in the UAE. A fixed-effects (FE) model was used to determine the factors associated with RTIs over time. The FE model removes the effect of time-invariant aspects from the independent variables, thus assessing the net impact of the independent variables on the outcome variable. The independent variables were dangerous driving behaviors defined as a sudden turn, neglect and lack of attention, and excess speed. The outcome variables were the total number of road traffic deaths and injuries.
\end{abstract}

Results: Road traffic deaths, severe injuries, and moderate injuries remained constant from 2012 to 2016 but mild injuries decreased starting 2013. Human errors such as a sudden turn (22\%), excess speed (12\%) and lack of road user appreciation (12\%) play a central role in road traffic injuries. The number of fines issued to drivers ( $66 \%$ for speeding) increased by $50 \%$ in the five year period.

Conclusion: Road traffic injuries in the UAE remained stable from 2012 to 2016 despite an increase in traffic fines issued to drivers. Human errors continue to be a major cause of these injuries. Additional enforcement strategies are needed to address this health burden.

Keywords: prevention, road traffic injuries, human error, traffic fines, United Arab Emirates

\section{Introduction}

Every day more than 3,600 lives are lost due to fatal road traffic injuries (RTIs), resulting in more than 1.3 million deaths per year (Khalil et al., 2018). The main risk factors include speeding, refusal to wear a seat belt, careless driving, drink driving, speaking over the phone or texting while driving (World Health Organization, 2015). The majority of victims are adolescents and young people under 30 years of age (GBD Collaborators on Disease and Injury Incidence and Prevalence, 2017). Globally, RTIs in 2016 caused a loss of 10 million years of life lost due to disability and 64 million disability-adjusted life years (GBD Collaborators on Disease and Injury Incidence and Prevalence, 2017). The estimated gross domestic product lost due to RTIs is estimated at $1.3 \%$ (World Health Organization, 2015). The Eastern Mediterranean Region, comprised of 22 countries, has the second highest road traffic fatality rates in the world and more than double the average rate of high-income countries globally (World Health Organization, 2010, 2015; Mokdad et al., 2016). The road traffic injury deaths in the Region have increased 27\% from 1990 to 2016 (GBD Collaborators on Disease and Injury Incidence and Prevalence, 2017). This is particularly relevant in the United Arab Emirates (UAE), not only in deaths but also in serious injuries. There has been a $454 \%$ increase in disability adjusted life years due to RTIs from 1990 to 2016 in the UAE (GBD Collaborators on Disease and Injury Incidence and Prevalence, 2017). The UAE has a dense road network and high levels of car ownership. In 2016, there were 3.39 million registered vehicles compared to 2.67 million registered vehicles in 2012, a 30\% increase over four years. Approximately $45 \%$ of all road traffic injuries in the UAE were by drivers 18 to 35 years of age (Afroza \& Rouf, 2017). Rollover crashes with a high risk of ejection was found to be a frequent cause of injury in young UAE-national, male drivers (Grivna et al., 2013). A panel of medical and 
public health specialists and various government health agencies commissioned to report on the health status of the UAE population found that injury caused $17 \%$ of mortality for all age groups in UAE (Loney et al., 2013). A study in Al-Ain city found that $40 \%$ of distracted drivers involved in road traffic collisions were using mobile phones (Grivna et al., 2013). An investigation of official police records, survey of road users and interview of traffic safety experts in the UAE confirmed that driving behavior is a major contributing factor to road safety (Hassan, Hawas, \& Maraqa, 2012). The most common driving violations in UAE are excessive speeding, neglecting indicators, tailgating, and jumping red traffic lights (Hammoudi, 2014). Compard with Europe, the three main killers on Europe's roads were speed, non-use of seat belt, and drink driving (European Transport Safety Council, 2011).

Measures to reduce and prevent RTIs focus on installing automated traffic monitoring systems and enforcing stricter road traffic laws by issuing fines (DeNicola, Aburizaize, Siddique, Khwaja, \& Carpener, 2016). The widespread awareness of road safety problems in UAE forsters the role of the government to implement such measures (Dawson, 1999). A meta-analysis of changes in compliance with road traffic laws or changes in collisions due to increases in traffic fine amounts was performed in 2016 and found that only a small reduction in fatal accidents was associated with increased penalties (Elvik, 2016). The link between road traffic collisions and causes is not fully understood (Araar \& El Tayeb, 2013; Ahmed, 2002; Al-Dah, 2010) and this impedes progress towards the UAE Vision 2021 to halve the number of road traffic deaths by 3 per 100,000 population with only 3 years remaining. The aim of this paper was to investigate the main causes and consequences of road traffic injuries (RTIs) in the United Arab Emirates (UAE) and the effect of traffic fines on these injuries.

\section{Methods}

We analysed two data sources. Firstly, secondary data on road traffic deaths and injuries from 2012 to 2016 ( $n=$ 39,384 ) stratified by outcome (mild injury, moderate injury, severe injury, and death). Secondly, traffic fines from the same time period ( $\mathrm{n}=51.1$ million) were stratified by cause ( 54 causes) and UAE emirate (Abu Dhabi- UAE capital, represents $85 \%$ of the land, Ajman-smallest emirate, Dubai, Fujaira, Ras el Khaimah (RAK), Sharjah and Umm El-Qaiwain). Both data sets were obtained from the official data portal of the UAE government and included only crashes that the police are called on-site (UAE Government, 2018).

Descriptive statistics were used to analyse the causes of fatal road traffic deaths and non-fatal injuries. A fixedeffects (FE) model was used to determine the factors associated with RTIs over time. The FE model removes the effect of time-invariant aspects from the independent variables, thus assessing the net impact of the independent variables on the outcome variable. The independent variables were dangerous driving behaviors defined as a sudden turn, neglect and lack of attention, excess speed, and driving under influence of alcohol. The outcome variables were the total number of road traffic deaths and injuries. We also used a dummy variable for each Emirate to estimate the pure effect of the independent variables on the outcome variable by controlling for the unobserved heterogeneity. Each dummy variable absorbed the effect of a particular Emirate. In addition, we performed the Hausman test to determine if the FE model was the best fit for our dataset and tested for cross-sectional dependence using the Breusch-Pagan test. In order to test the heteroscedasticity, we performed a modified Wald test for heteroscedasticity and used the option 'robust' to obtain heteroscedasticity-robust standard errors, known as the Huber-White or sandwich estimators. To test for serial correlation, we used a Lagram multiplier test. It was essential to test for the omitted variable bias in the model as it is closely related to the assumption that the error term and the independent variables in the model are not correlated $(\mathrm{E}(\mathrm{e} \mid \mathrm{X})=0)$. Therefore, we tested for omitted-variable bias through the use of the ovtest command. A P-value of $<0.05$ was considered statistically significant. The data was analyzed using STATA (StataCorp LLC, Texas, USA) version 12.

\section{Results}

Over a period of five years (2012-2016), 90\% of road traffic incidents in the UAE did not result in a death or injury. The rates of deaths (704 in 2012 to 782 in 2016), severe injuries, and moderate injuries remained constant over time but the mild injury rate per 100,000 population decreased starting 2013 from 3,823 to 3,110 in 2016, as shown in Figure 1. 


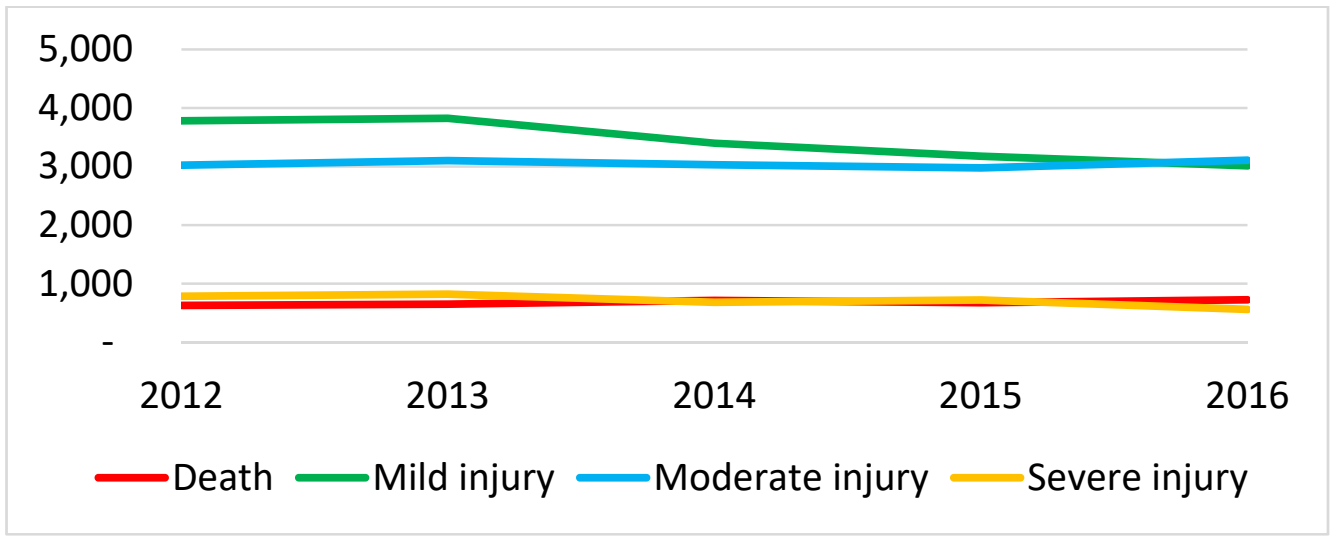

Figure 1. Rate of road traffic deaths and injuries per 100,000 population in the UAE, 2012-2016

The majority of road traffic deaths and injuries occurred in the Emirate of Abu Dhabi (Abu Dhabi), followed by the Emirate of Dubai, as shown in Figure 2. Only Abu Dhabi showed a decrease over time, while the 6 other Emirates showed relatively no change, especially in the Emirate of Um El-Quwain with an average of 90 cases per year.

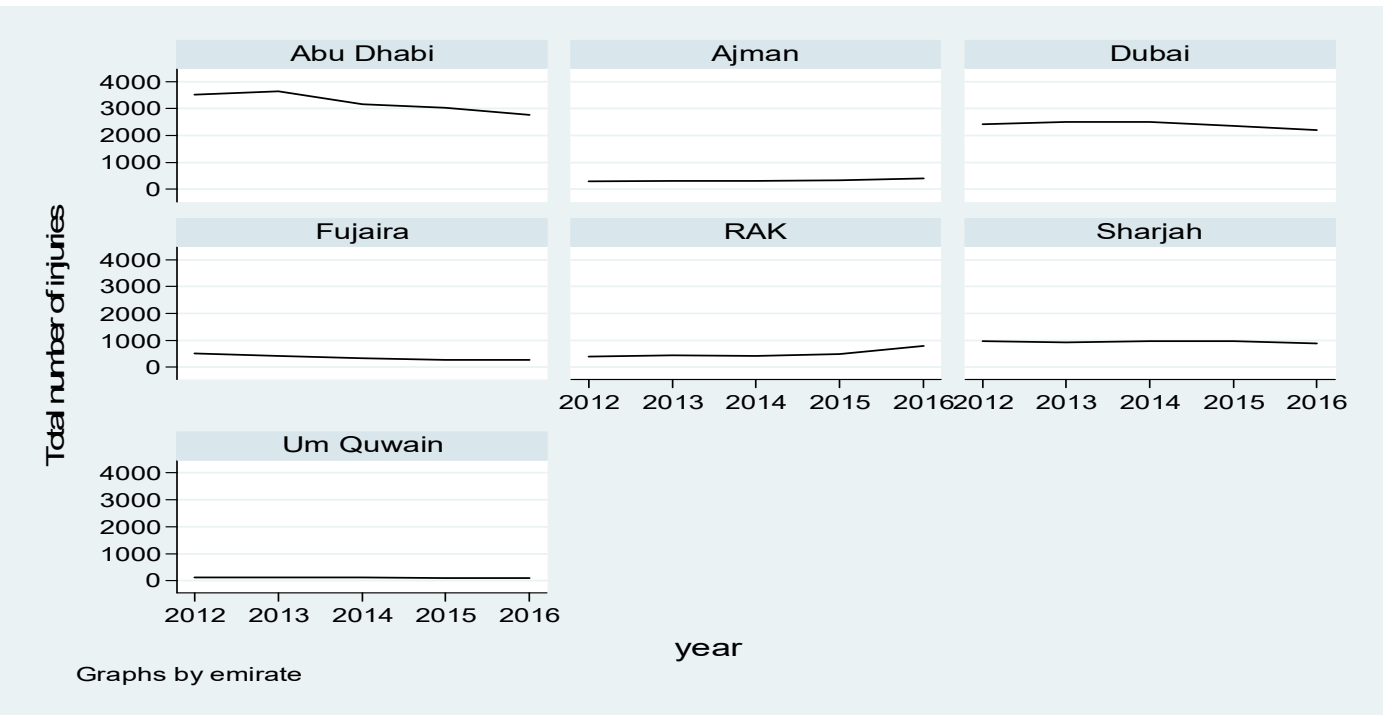

Figure 2. Number of road traffic deaths and injuries in the seven Emirates

Analysis of UAE road traffic statistics from 2012 to 2016 aggregated showed that $98.8 \%$ of incidents were attributed to human factors, $0.2 \%$ to road factors, and $1.0 \%$ to a vehicle factor. Figure 3 demonstrates the main causes of road traffic deaths during the five year period. A sudden turn was the major cause of all RTIs (22\%), followed by excess speed (12\%), lack of road user appreciation (12\%), neglect and lack of attention, and not leaving a sufficient distance between cars (10\%). Driving under the influence of alcohol and crossing the red signal contributed $2 \%$ each. 

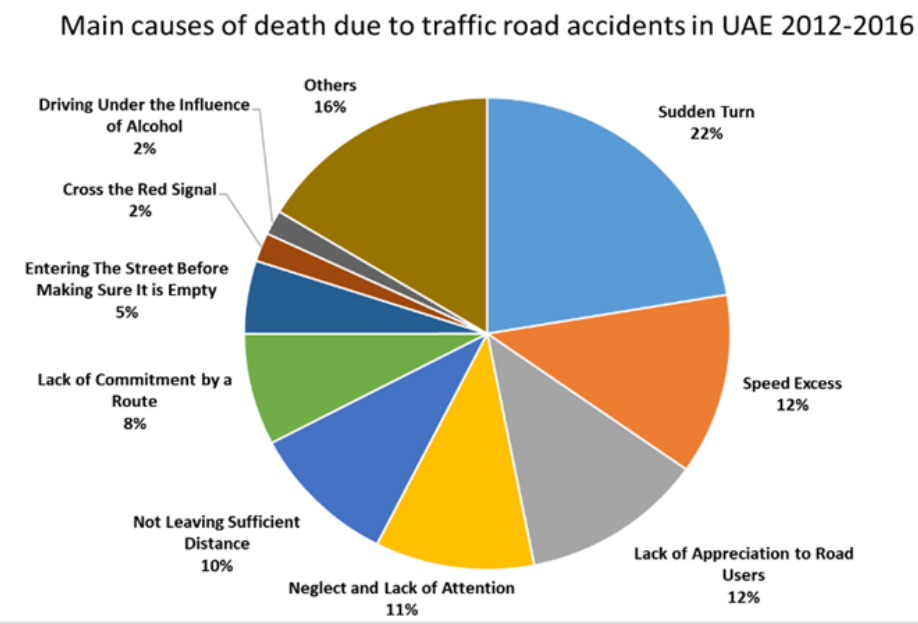

Figure 3. Causes of road traffic deaths in the UAE, 2012-2016

The ranking of RTI causes differs in accordance with the injury outcome. Table 1 indicates that a sudden turn, excessive speed, and a lack of appreciation to road users were main causes of death. A sudden turn, lack of appreciation to road users, as well as neglect were main causes of severe injury. A sudden turn, not leaving a sufficient distance, a lack of appreciation to road users, and neglect were main causes of moderate injury. Finally, a sudden turn, not leaving a sufficient distance, and crossing the red signal were main causes of mild injury.

Table 1. Ranking of RTI causes according to injury type, 2012-2016

\begin{tabular}{|c|c|c|c|c|c|c|c|c|c|c|}
\hline Causes of Traffic Accidents & Death & $\%$ & $\begin{array}{l}\text { Severe } \\
\text { injury }\end{array}$ & $\%$ & $\begin{array}{l}\text { Mode } \\
\text {-rate } \\
\text { injury }\end{array}$ & $\%$ & $\begin{array}{l}\text { Mild } \\
\text { injury }\end{array}$ & $\%$ & $\begin{array}{l}\text { Tota } \\
\text { l }\end{array}$ & $\%$ \\
\hline Sudden turn & 758 & $22 \%$ & 750 & $21 \%$ & 3150 & $21 \%$ & 3258 & $19 \%$ & 7916 & $20 \%$ \\
\hline Speed excess & 420 & $12 \%$ & 279 & $8 \%$ & 1211 & $8 \%$ & 825 & $5 \%$ & 2735 & $7 \%$ \\
\hline Lack of road user appreciation & 412 & $12 \%$ & 478 & $13 \%$ & 1527 & $10 \%$ & 1011 & $6 \%$ & 3428 & $9 \%$ \\
\hline Neglect and lack of attention & 359 & $11 \%$ & 409 & $11 \%$ & 1542 & $10 \%$ & 1057 & $6 \%$ & 3367 & $9 \%$ \\
\hline Not leaving a sufficient distance & 334 & $10 \%$ & 365 & $10 \%$ & 1903 & $12 \%$ & 2807 & $16 \%$ & 5409 & $14 \%$ \\
\hline Lack of route commitment & 259 & $8 \%$ & 259 & $7 \%$ & 1202 & $8 \%$ & 1356 & $8 \%$ & 3076 & $8 \%$ \\
\hline $\begin{array}{l}\text { Entering the street before } \\
\text { making sure it is empty }\end{array}$ & 170 & $5 \%$ & 272 & $8 \%$ & 1205 & $8 \%$ & 1674 & $10 \%$ & 3321 & $8 \%$ \\
\hline Crossing the red signal & 67 & $2 \%$ & 136 & $4 \%$ & 739 & $5 \%$ & 2238 & $13 \%$ & 3180 & $8 \%$ \\
\hline $\begin{array}{l}\text { Driving under the influence of } \\
\text { alcohol }\end{array}$ & 57 & $2 \%$ & 65 & $2 \%$ & 325 & $2 \%$ & 668 & $4 \%$ & 1115 & $3 \%$ \\
\hline Others & 554 & $16 \%$ & 553 & $16 \%$ & 2434 & $16 \%$ & 2296 & $13 \%$ & 5837 & $15 \%$ \\
\hline Total & 3390 & $100 \%$ & 3566 & $100 \%$ & 15238 & $\begin{array}{l}100 \\
\%\end{array}$ & 17190 & $\begin{array}{l}100 \\
\%\end{array}$ & $\begin{array}{l}3938 \\
4\end{array}$ & $\begin{array}{l}100 \\
\%\end{array}$ \\
\hline
\end{tabular}

\section{Traffic Fines}

From 2012 to 2016 traffic fines increased approximately 50\% in the UAE, from 8.2 million to 12.0 million (see supplementary data Table 3). On average in the 5 year study period there were 10.2 million traffic fines per year and approximately $45 \%$ and $32 \%$ of all the fines were issued in the cities of Abu Dhabi and Dubai, respectively. Approximately $66 \%$ of the traffic fines were related to speeding (see supplementary data Table 4 ). The majority of speeding fines $(62 \%)$ were related to speeding that did not exceed $30 \mathrm{~km}$ above the maximum level, followed by $16 \%$ not more than $40 \mathrm{~km} / \mathrm{h}$ above, and $12 \%$ at not more than $10 \%$ above (see supplementary data Table 5). 


\section{Fixed-Effects Model}

The fixed-effects model regression demonstrated that on average, every 10 crashes related to a sudden turn results in eight health-related injuries; every 10 crashes related neglect and lack of attention result in 21 total health-related injuries (Table 2). Every 10 crashes related to excess speed result in 38 total health-related injuries, while every 10 crashes related to driving under influence of alcohol result in 17 total health-related injuries. All Emirates showed statistically significant lower RTIs than Abu Dhabi, except Dubai. On average, the Emirate of Ajman had 1,476 number of accidents annually which resulted in the negative health-related outcome; however, it was less than that of Abu Dhabi. Moreover, the Emirate of Fujairah had 1,361 RTIs a year, which resulted in a health-related outcome that was less than in Abu Dhabi. At the same time, the Emirate of Ras Al-Khaima had 1,320 number of RTIs annually, affecting the health of less people than in Abu Dhabi. On average, the Emirate of Sharjah had 1,057 number of accidents annually, resulting in a less serious health-related outcome than in Abu Dhabi. Finally, the Emirate of Um Al-Quwain had 1,535 number of accidents a year, which resulted in the negative health-related outcome that was not as great as in Abu Dhabi.

Table 2. Fixed effects regression model of dangerous driving behaviour

\begin{tabular}{lll}
\hline Variable & Fixed effect & Robust \\
\hline Sudden turn & $0.85^{* *}$ & $0.85^{* *}$ \\
Neglect and lack of attention & $2.17^{* * *}$ & $2.17^{* * *}$ \\
Excess speed & $3.85^{* * *}$ & $3.85^{* * *}$ \\
Driving under influence of alcohol & $1.71^{*}$ & 1.71 \\
Abu Dhabi & Reference & \\
Ajman & $-1476^{* * *}$ & \\
Dubai & -34 & \\
Fujairah & $-1361^{* * *}$ & \\
Ras Akhaima & $-1320^{* * *}$ & \\
Sharjah & $-1057^{* * *}$ & \\
Um EL-Quwain & $-1535^{* * *}$ & 35 \\
Constant & $604^{* * *}$ & \\
N & 35 & 0.99 \\
r2 & 0.79 & 79.4 \\
Rmse & 79.4 & \\
\hline
\end{tabular}

Legend: ${ }^{*}<<0.05 ; * * \mathrm{p}<0.01 ; * * * \mathrm{p}<0.001$.

\section{Discussion}

RTIs are one of the most important problems of the UAE as they cause health and material losses every day. In this study RTI data and panel data on traffic fines for the years 2012 to 2016 were analyzed using a fixed effect regression to determine the causes of these injuries and the effect of fines on the number of deaths and injuries. We found RTI deaths and severe/moderate injuries remained constant over the five year period, despite the increase in fines. Human errors such as a sudden turn, neglect and lack of attention, and excessive speed play a significant role in RTIs occuring in the UAE.

Different countries implement various systems of fines, demerit points and sanction schemes in an attempt to enforce traffic laws. Effective practices have been used in such countries as Canada, Sweden, and the United Kingdom. For example Canada has a 2-year black point validity and in the UK the black points have a 3-year validity (Morley et al., 2017). However, in the UAE, it is only 1 year, thus it may be useful for the UAE to consider extending the time period as the increase of the demerit point validity on the driver's record for a longer time period emphasises the seriousness and severity of committing violations while driving. Driver training courses in the UK enable drivers to have an alternative to receiving fines and demerit points (Morley et al., 2017) and this strategy could be of interest to pursue in the UAE. In 2017, the special amended federal traffic law was developed 
and implemented in the country. The new law aims to protect the lives and safety of road users and reduce the number of RTIs (The official portal of UAE Government, 2018). The UAE is investing in the fixed speed and mobile cameras to reduce the rate of driving violations, based on the French success. Carnis and Blais demonstrated that according to the installation of fixed and mobile cameras in France the fatality rate decreased by more than $20 \%$ and non-fatal traffic injuries were reduced from $26 \%$ in 2002 to just less than $1 \%$ in 2010 (Carnis \& Blais, 2013). This helps the European Union towards its ambitious goal of a 50\% reduction in road deaths by 2020 (Gössling, 2017) based on improved law enforcement strategies to prevent excessive speeding and reduce drinking and driving (ICF Consulting, 2003). These law enforcement strategies are also applicable in the UAE to reduce the RTI burden, including a national alcohol abuse registry (Osman et al., 2015).

Road traffic trauma registries that include data on evidence-based prevention measures such as the use of safety restraints and helmets by road user type would also be a vital step towards the design of prevention strategies (Grivna et al., 2013). This information would assist efforts to decrease the high occurrence of traffic-related head injuries among children and young people in the UAE as unrestrained rear-seat passengers (Grivna et al., 2013; Bener et al., 1998). Furthermore, as this study showed that human errors were a major cause of deaths and injuries, richer data are needed to understand how enforcement strategies can be utilised to change human behavior (Bener et al., 2012; Araar \& El-Tayeb, 2013).

\subsection{Strengths and Limitations}

This study has several strengths. The RTI data were analysed over a period of five years to examine trends and the health outcomes stratified to include deaths, severe and mild injuries. The panel data on traffic fines were detailed enough to ascertain which human errors need to be targeted and the fixed-effects modeling estimates for each Emirate are useful for targeting prevention efforts. But the data did not include demographic and economic variables, which limits our ability to investigate the role of socioeconomic factors. Furthermore, the road traffic injury data may be underestimations as not all road traffic incidents may be captured in the official statistics.

\section{Conclusions}

Road traffic injuries in the UAE remained stable from 2012 to 2016 despite an increase in traffic fines issued to drivers. Human errors continue to be a major cause of these injuries. Additional enforcement strategies are needed to address this health burden.

\section{Competing Interests Statement}

The authors declare that there are no competing or potential conflicts of interest.

\section{References}

Afroza, S., \& Rouf, R. (2017). A Statistical Study on Young UAE Driver's Behavior towards Road Safety. World Academy of Science, Engineering and Technology, International Journal of Social, Behavioral, Educational, Economic, Business and Industrial Engineering, 11(10), 2438-2442.

Ahmed, M. E. H. (2002). Epidemiology and economic impact of road traffic accidents in the United Arab Emirates (PhD Thesis). University of Abertay Dundee, Dundee, Scotland.

Al-Dah, M. K. (2010). Causes and consequences of road traffic crashes in Dubai, UAE and strategies for injury reduction (Ph.D. Thesis, Loughborough University, Loughborough, UK). https://dspace.lboro.ac.uk/dspace-jspui/bitstream/2134/5965/1/Aldah.

Araar, A., \& El Tayeb, A. A. (2013). Mining road traffic accident data to improve safety in Dubai. Journal of Theoretical \& Applied Information Technology, 47, 911.

Bener, A., Al-Salman, K. M., \& Pugh, R. N. H. (1998). Injury mortality and morbidity among children in the United Arab Emirates. European Journal of Epidemiology, 14, 175-178. https://doi.org/10.1023/a:1007444109260

Bener, A., Hussain, S. J., Al Malki, M. A., Shotar, M. M., Al Said, M. F., \& Jadaan, K. S. (2010). Road traffic fatalities in Qatar, Jordan and the UAE: Estimates using regression analysis and the relationship with economic growth. Eastern Mediterranean Health Journal, 16, 318-323. https://doi.org/10.26719/2010.16.3.318

Carnis, L., \& Blais, E. (2013). An assessment of the safety effects of the French speed camera program. Accident Analysis \& Prevention, 51, 301-309. https://doi.org/10.1016/j.aap.2012.11.022

Dawson, P., \& Bener, A. (1999). Safer roads for children in United Arab Emirates. Eastern Mediterranean Health Journal, 5, 277-281. 
DeNicola, E., Aburizaize, O. S., Siddique, A., Khwaja, H., \& Carpenter, D. O. (2016). Road traffic injury as a major public health issue in the Kingdom of Saudi Arabia: A Review. Frontiers in public health, 4, 215. https://doi.org/10.3389/fpubh.2016.00215

Elvik, R. (2016). Association between increase in fixed penalties and road safety outcomes: A meta-analysis. Accident Analysis \& Prevention, 92, 202-210. https://doi.org/10.1016/j.aap.2016.03.028

European Transport Safety Council. (2011). Traffic law enforcement across the EU: Tackling the three main killers on Europe's roads. Retrieved from http://www.trb.org/Main/Blurbs/164901.aspx

GBD Collaborators on Disease and Injury Incidence and Prevalence. (2017). Global, regional, and national incidence, prevalence, and years lived with disability for 328 diseases and injuries for 195 countries, 1990 2016: A systematic analysis for the Global Burden of Disease Study 2016. The Lancet, 390, 1211-1259. https://doi.org/10.1016/S0140-6736(17)32154-2

Gössling, S. (2017). Police perspectives on road safety and transport politics in Germany. Sustainability, 9, 1771. https://doi.org/10.3390/su9101771

Grivna, M., Barss, P., Stanculescu, C., Eid, H. O., \& Abu-Zidan, F. M. (2013). Child and youth traffic-related injuries: Use of a trauma registry to identify priorities for prevention in the United Arab Emirates. Traffic Injury Prevention, 14, 274-282. https://doi.org/10.1080/15389588.2012.711498

Hammoudi, A. A. (2014). Causes and strategies to reduce road traffic accidents in Abu Dhabi (Phd Thesis). Cardiff Metropolitan University,. Cardiff.

Hassan, M. N., Hawas, Y. E., \& Maraqa, M. A. (2012). A holistic approach for assessing traffic safety in the United Arab Emirates. Accident Analysis \& Prevention, 45, 554-564. https://doi.org/10.1016/j.aap.2011.09.009

ICF Consulting. (2003). Cost-benefit analysis of road safety improvements. Final Report.

Khalil, I., El Bcheraoui, C., Charara, R., Moradi-Lakeh, M., Afshin, A., Kassebaum, N. J., . . G. B. D. Eastern Mediterranean Region Transportation Injuries Collaborators. (2018). Transport injuries and deaths in the Eastern Mediterranean region: Findings from the Global Burden of Disease 2015 Study. International Journal of Public Health, 63, 187-198. https://doi.org/10.1007/s00038-017-0987-0

Loney, T., Aw, T.-C., Handysides, D. G., Ali, R., Blair, I., Grivna, M., .. . El-Obaid, Y. (2013). An analysis of the health status of the United Arab Emirates: The 'Big 4' public health issues. Global Health Action, 6, 42-51. https://doi.org/10.3402/gha.v6i0.20100

Mokdad, A. H., Forouzanfar, M. H., Daoud, F., El Bcheraoui, C., Moradi-Lakeh, M., Khalil, I., . . Barber, R. M. (2016). Health in times of uncertainty in the eastern Mediterranean region, 1990-2013: A systematic analysis for the Global Burden of Disease Study 2013. The Lancet Global Health, 4, e704-e713. https://doi.org/10.1016/S2214-109X(16)30168-1

Morley, A., Morris, A., Semaan, M. A., \& Hancox, G. (2017). A guide for policy makers: on reducing road fatalities.

Osman, O. T., Abbas, A. K., Eid, H. O., Salem, M. O., \& Abu-Zidan, F. M. (2015). Alcohol-related road traffic injuries in Al-Ain city, United Arab emirates. Traffic Injury Prevention, 16, 1-4. https://doi.org/10.1080/15389588.2014.895923

The Official Portal of the UAE Government. (2018). Legal provisions. Retrieved from https://government.ae/en/information-and-services/justice-safety-and-the-law/road-safety

UAE Government. (2018). Official data portal of the UAE government. Retrieved from http://bayanat.ae/en

WHO Regional Office for the Eastern Mediterranean. (2010). Eastern Mediterranean status report on road safety: Call for action. Cairo: World Health Organization.

World Health Organization [WHO]. (2015). Global status report on road safety 2015. Geneva: World Health Organization. http://www.who.int/violence_injury_prevention/road_safety_status/2015/en/

\section{Copyrights}

Copyright for this article is retained by the author(s), with first publication rights granted to the journal.

This is an open-access article distributed under the terms and conditions of the Creative Commons Attribution license (http://creativecommons.org/licenses/by/4.0/). 